\title{
Miopatia mitocondrial: relato de dois casos
}

\author{
Mitochondrial myopathy:twocase reports
}

\author{
Sara Patrícia Grebos ${ }^{1}$ \\ Tatiana de Almeida ${ }^{2}$ \\ Karine Horta Barbosa ${ }^{3}$ \\ Michele Agostini Buquera ${ }^{4}$ \\ Ana Tereza Ramos Moreira ${ }^{5}$
}

\section{RESUMO}

Miopatia mitocondrial é um distúrbio genético caracterizado por oftalmoplegia externa crônica progressiva e ptose palpebral superior, apresentandose a partir da $3^{\underline{a}}$ e $4^{\mathrm{a}}$ década de vida. Os autores revisaram a literatura e relataram 2 casos do sexo feminino com diplopia à leitura.

Descritores: Miopatias mitocondriais/etiologia; Oftalmoplegia externa progressiva crônica; Diplopia; Relatos de casos [tipo de publicação]

\section{INTRODUÇÃO}

A primeira descrição de um paciente com miopatia mitocondrial e deficiência na função da cadeia respiratória foi realizada por Luft et al. há 40 $\operatorname{anos}^{(1)}$. Estudos subsequientes realizados relataram uma combinação de métodos bioquímicos e morfológicos para identificar pacientes com desordens mitocondriais ${ }^{(1)}$.

Oftalmoplegia externa crônica progressiva (OECP) é uma desordem caracterizada por paralisia lentamente progressiva dos músculos extra-oculares. Os pacientes geralmente apresentam ptose palpebral superior progressiva, simétrica, bilateral, seguida de OECP meses ou anos mais tarde. Músculos ciliares e da íris não são envolvidos ${ }^{(2)}$. A OECP é a manifestação mais freqüente das miopatias mitocondriais. OECP em associação com mutações do DNA mitocondrial (mtDNA) pode ocorrer na ausência de qualquer outro sinal clínico, mas também está associado com fraqueza esquelética ${ }^{(3)}$.

Na miopatia mitocondrial ocorre aumento do número de mitocôndrias na fibra muscular, aumento do tamanho ou a existência de inclusões cristalinianas anormais nestas mitocôndrias. $\mathrm{O}$ exame histoquímico revela um padrão de cores nas fibras musculares que resulta do acúmulo de mitocôndrias aumentadas de tamanho. Ao exame de mancha tricômica as fibras se coram de azul, enquanto as mitocôndrias da periferia se coram de vermelho forte, tendo o aspecto " Ragged red fibers"(4-5).

A OECP pode ser classificada em três entidades: a distrofia muscular óculo-faríngea, a síndrome de Kearns-Sayre e a miopatia ocular pura ${ }^{(6)}$.

$\mathrm{Na}$ distrofia muscular óculo-faríngea a OECP está associada a disfagia. $\mathrm{O}$ início é na quinta década de vida e a herança é autossômica dominante. A disfagia é proeminente, sendo a alimentação feita através de sonda nasogástrica nos estágios finais da moléstia. Há importante comprometimento da musculatura inervada pelo trigêmeo e pelos pares bulbares e ptose palpebral bilateral. Há com o decorrer da doença o comprometimento da musculatura das cinturas (escapular e pélvica). A creatinofosfoquinase (CPK) é normal, a eletroneuromiografia e a biópsia de músculo mostram um padrão miopático. Casos com paresia palatal têm melhora de seus sintomas com elevadores palatais. Não há medicação específica para esse tipo de enfermidade ${ }^{(6)}$.

A síndrome de Kearns-Sayre (SKS) é de herança materna e inicia-se 
normalmente antes dos 15 anos de idade. Entidade caracterizada por tríade clínica: oftalmoplegia externa progressiva, degeneração pigmentar de retina e defeitos cardíacos de condução. Geralmente a ptose palpebral superior é a primeira manifestação seguida de oftalmoplegia, retinite atípica e bloqueios na condução cardíaca ${ }^{(7)}$. A retinite é atípica pois raramente leva a déficit da acuidade visual. Os defeitos de condução são graves e por vezes requerem o uso de marcapassos cardíacos. Outras associações ${ }^{(8)}$ incluem surdez neurossensorial, baixa estatura, retardo da maturação sexual e comprometimento cerebelar e vestibular. A proteína do líquido cefalorraquidiano $^{(7)}$ está geralmente elevada acima de $100 \mathrm{mg} / 100 \mathrm{ml}$. A biópsia muscular mostra, à microscopia óptica fibras do tipo "ragged red" sendo que na microscopia eletrônica aparecem alterações mitocondriais e mais recentemente têm sido demonstradas deleções do DNA mitocondrial. Não há medicação específica para esta entidade ${ }^{(9)}$.

A miopatia ocular pura possui herança autossômica dominante, inicia-se na infância, adolescência ou idade adulta com ptose palpebral superior, seguida de oftalmoplegia externa progressiva bilateral e simétrica que leva, nos estádios finais, a uma impossibilidade de movimentação dos globos oculares. Raramente há diplopia e a fraqueza dos músculos da face e da cintura escapular ocorre em $20 \%$ dos casos. Os reflexos tendinosos estão todos hipoativos e a musculatura ocular intrínseca está sempre preservada. Não há medicação específica para esta moléstia( ${ }^{(6)}$.

\section{OBJETIVO}

Relatar dois casos de miopatia mitocondrial pura iniciados aos 20 e 30 anos de idade.

\section{RELATO DOS CASOS}

O primeiro caso, R.G. M., 40 anos, feminino, compareceu ao serviço do HOP apresentando quadro clínico de evolução desde os 30 anos com ptose palpebral superior progressiva em ambos os olhos há 10 meses. As queixas principais eram ptose e dificuldade para a leitura (Fig.1). À inspeção, havia ptose assimétrica, com rima palpebral do olho direito (OD) de 9,0 mm e do olho esquerdo(OE) de 6,0 mm (Fig.2). A função do elevador do OD era $11 \mathrm{~mm}$ e do OE, $7 \mathrm{~mm}$. Ao exame de motilidade ocular extrínseca revelava importante limitação muscular no teste de versões e ducções, ausência de convergência e ausência do reflexo de Bell. Acuidade visual com correção 6/6 (AO), fundoscopia normal e tonometria $12 \mathrm{mmHg}$ (AO). Ao exame clínico sistêmico apresentou pressão arterial baixa. Exames normais de ECG, planigrafia de mediastino, tomografia de tórax, CPK, LDH e VHS. Exame endocrinológico e exames laboratoriais de TSH, T3 e T4 normais. Ao exame neurológico e laboratorial através de eletromiografia apresentou padrão miopático não específico e, na biópsia muscular revelou-se miopatia mitocondrial, sugestivo de deficiência de citocromo c-oxidase.

O segundo caso, A.F.L, 23 anos, feminino, compareceu ao serviço do HC-UFPR apresentando quadro clínico de ptose palpebral progressiva com evolução acentuada há 3 anos em AO. Refere início da ptose na infância e mais tarde diplopia para a leitura. Ao exame de motilidade ocular apresentava limitação nas versões com exotropia (XT) alternante de 8 dioptrias prismáticas (dp) pelo método Krimsky e ausência do reflexo de Bell. Acuidade visual era $6 / 9$ com correção $(-1,00 * 0$ $\mathrm{AO})$ em ambos os olhos (AO) e fundoscopia normal. A rima palpebral media $5 \mathrm{~mm}$ AO e a função do elevador do olho direito era de $8 \mathrm{~mm}$ e olho esquerdo de $9 \mathrm{~mm}$. Ao exame clínico sistêmico apresentava pressão arterial baixa. Os exames cardíacos e ECG apresentavam- se normais. Exame endocrinológico e exames laboratoriais de TSH, T3 e T4 normais. Ao exame neurológico através da eletromiografia observou-se valores dentro dos limites da normalidade e a biópsia muscular revelou miopatia mitocondrial sem especificar deficiência de citocromo oxidase.

Em ambos os casos foi prescrito lentes prismáticas com base nasal, no primeiro caso com 2 prismas em cada lente associado ao grau para a presbiopia e no segundo caso o grau refrativo adicionado de 4 prismas em cada lente.

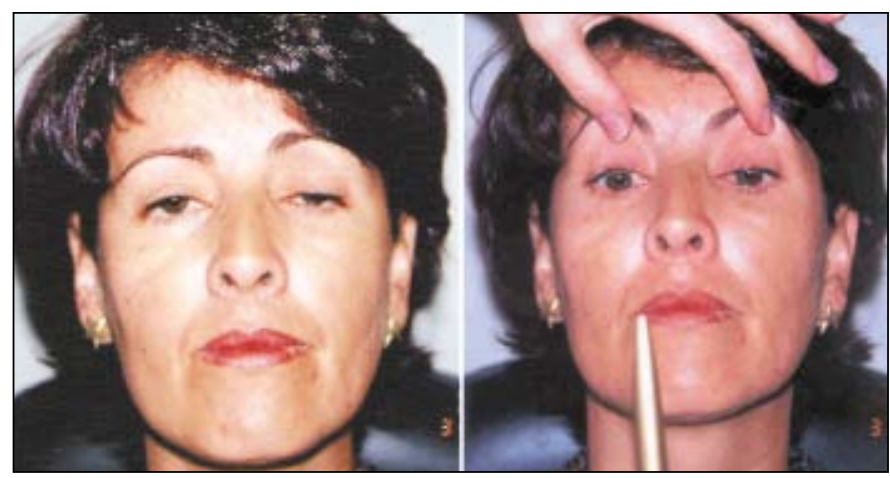

Figura 1 - Ptose palpebral e insuficiência de convergência

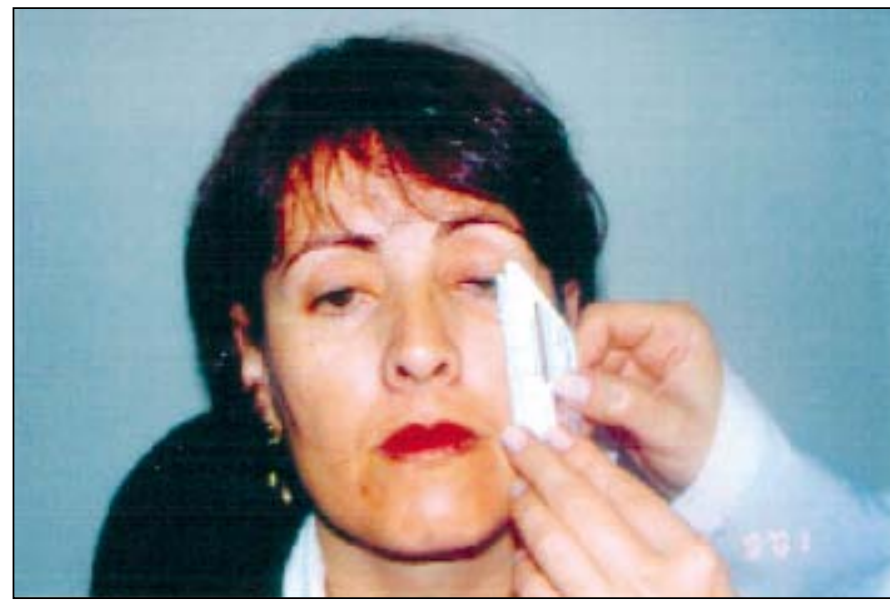

Figura 2 - Medida da fenda palpebral 


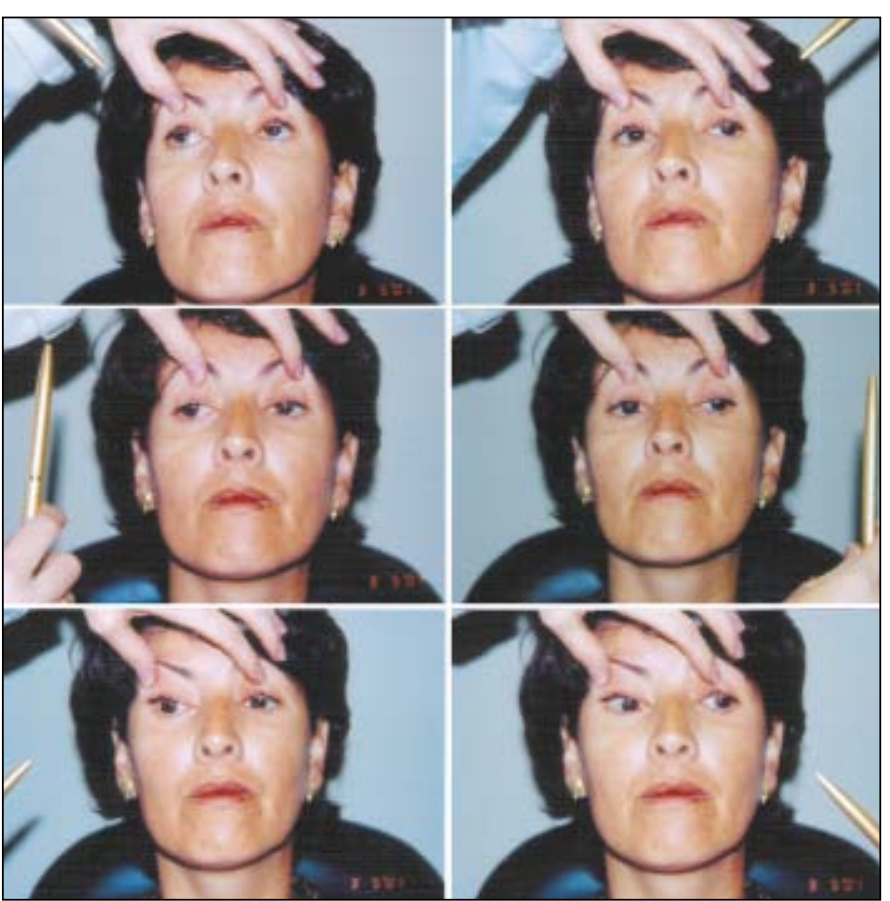

Figura 3 - Limitação muscular da abdução e adução

\section{DISCUSSÃO}

A OECP inicia-se normalmente em adultos jovens. A ptose palpebral é usualmente, o primeiro sinal clínico e a oftalmoplegia pode não se tornar aparente por meses ou anos. Normalmente a ptose é bilateral e simétrica e, com a progressão, o paciente pode usar o músculo frontal para elevar as pálpebras, adotando uma posição de elevação do queixo e cabeça ${ }^{(10-11)}$.

Devido à natureza simétrica desta desordem, os pacientes freqüentemente não reclamam de diplopia e podem não perceber a diminuição da motilidade até se tornar severa. Em muitos casos a mirada inferior é mais preservada do que a mirada superior ou do que os movimentos horizontais. O curso da OECP é caracterizado por progressão constante sem períodos de remissão ou exacerbação. Os pacientes também se podem queixar de hiperemia ocular devido a ceratopatia de exposição causada pela paralisia de Bell ${ }^{(12)}$. O diagnóstico de miopatia mitocondrial quase sempre é suspeitado na presença de oftalmoplegia, o que não ocorre quando predominam sinais e sintomas de acometimento do sistema nervoso central ${ }^{(5)}$.

Na síndrome de Kearns-Sayre ou SKS, as crianças são normais ao nascimento. A OECP e a retinopatia pigmentar aparecem antes dos vinte anos, sendo que a pigmentação retiniana tem aspecto de sal-e-pimenta, sem formação de espículas ósseas típicas da retinite pigmentosa. A oftalmoplegia geralmente precede o desenvolvimento de defeitos de condução cardíaca. Morte súbita pode ocorrer devido a esses distúrbios e os pacientes devem ser submetidos a exames cardíacos regulares ${ }^{(7-13)}$.

No diagnóstico diferencial da miopatia mitocondrial é importante que sejam incluídos: miastenia gravis, orbitopatia de Basedow-Graves e distrofia oculofaringeal.
O diagnóstico histológico é fornecido através da biopsia muscular, nesses casos, pelo bíceps braquial, um músculo esquelético. A fibra do músculo extra-ocular apresenta maior poder oxidativo que os músculos esqueléticos, mesmo naqueles casos com miopatia mitocondrial. Entretanto, diferentemente do pressuposto, notou-se, na fibra do músculo extraocular, uma predominância quase absoluta de fibras do tipo II, fibras estas que são normalmente classificadas como anaeróbias e com baixo poder oxidativo. Através destes achados, concluiu-se que a fibra da musculatura extra-ocular apresenta características histoquímicas distintas e os critérios morfológicos para individualização da doença específica ainda não estão definidos ${ }^{(14)}$.

Em relação aos estudos genéticos tem-se demonstrado que a disfunção mitocondrial se deve a deleções do DNA mitocondrial, consequiente às mutações espontâneas ${ }^{(15)}$.

O tratamento instituído para a ptose palpebral deve ser cuidadoso, pois, a ausência do reflexo de Bell e a diminuição da força muscular após correção cirúrgica da ptose propiciam uma exposição corneana, com lubrificação insuficiente e conseqüentes complicações corneanas como ceratites de exposição. Ambos os casos foram orientados em relação às complicações decorrentes de uma possível correção cirúrgica e foi proposto observar a evolução da ptose. No caso da dificuldade de convergência para a leitura empregou-se o uso de prisma base nasal.

A cirurgia de estrabismo pode ser útil em alguns pacientes caso exista queixa de diplopia e desvio estável por muitos meses $^{(16)}$.

A miopatia mitocondrial é uma desordem complexa que requer o envolvimento de várias especialidades médicas, incluindo neurologia, cardiologia, oftalmologia e endocrinologia. É imperativo que os pacientes tenham um acompanhamento regular nestas áreas, uma vez que o prognóstico é reservado e a desordem é geralmente progressiva.

\section{ABSTRACT}

Mitochondrial myopathy is a genetic disorder characterized by chronic progressive external ophthalmoplegia and upper eyelid, ptosis which occurs before 30 to 40 years of life. The authors reviewed the literature and reported two cases of reading diplopia in female patients.

Keywords: Mitochondrial myopathies/etiology; Ophthalmoplegia, chronic progressive external/complications; Diplopia; Case reports [publication type]

\section{REFERÊNCIAS}

1. Larsson NG, Oldfors A. Mitochondrial myopathies. Acta Physiol Scand. 2001;171(3):385-93.

2. Carlow TJ, Depper MH, Orrison WW. MR of extraocular muscles in chronic progressive external ophthalmoplegia. AJNR Am J Neuroradiol. 1998;19(1): $95-9$ 
3. Kiyomoto BH, Tengan $\mathrm{CH}$, Moraes CT, Oliveira AS, Gabbai AA. Mitochondrial DNA defects in Brazilian patients with chronic progressive external ophthalmoplegia. J Neurol Sci. 1997;152(2):160-5.

4. Werneck LC, Abdalla H, Lohr A. Melas (mitochondrial encephalopathy, lactic acidosis and stroke-like episodes): relato de um caso. Arq Neuropsiquiatr. 1987;45(3):288-94.

5. Kiyomoto BH, Gabbai AA, Oliveira AS, Schmidt B, Lima JG. [Mitochondrial myopathy: report of 12 cases with histochemical study of the skeletal muscle]. Arq Neuropsiquiatr. 1991;49(3):272-8. Portuguese.

6. Gabbai AA., Oliveira ASB. Doenças dos músculos. In: Prado FC do P, Ramos J, Valle JR. Atualização terapêutica manual prático de diagnóstico e tratamento. 17å ed. São Paulo: Artes Médicas; 1995. p.707-8.

7. Cruz MW, André C, Hahn MD, Mattos JP, Maranhão Filho PA, Silva ES, et al. Síndrome de Kearns-Sayre: relato de caso com instalação rápida e documentação anátomo-patológica. Rev Bras Neurol. 1989;25(2):55-60.

8. Kalenak JW, Koller AE. Kearns-Sayre syndrome and primary open-angle glaucoma. Am J Ophthalmol. 1989;108(3):335-6.

9. Kosmorsky G, Johns DR. Neuro-ophthalmologic manifestations of mitochondrial DNA disorders: chronic progressive external ophthalmoplegia, Kearns-Sayre syndrome, and Leber's hereditary optic neuropathy. Neurol Clin. 1991;9(1):147-61. Erratum in: Neurol Clin. 1991;9(2):XII.
10. Cohen JM, Waiss B: Combination ptosis crutch and moisture chamber for management of progressive external ophthalmoplegia. J Am Optom Assoc. 1997;68(10):663-7.

11. Tosta ED. [Chronic progressive external ophthalmoplegia: I. A quantitative histochemical study of skeletal muscles]. Arq Neuropsiquiatr. 1988;46(2): 133-42. Portuguese.

12. Fraunfelder FT, Roy FH, Randall J. Chronic progressive external ophthalmoplegia. In: Fraunfelder FT, Roy FH, Randall J. Current ocular therapy. 5th ed. Pennsylvania: W.B. Saunders; 2000. p.208-10.

13. De Coo IF, Gussinklo T, Arts PJ, Van Oost BA, Smeets HJ. A PCR test for progressive external ophthalmoplegia and Kearns-Sayre syndrome on DNA from blood samples. J Neurol Sci. 1997;149(1):37-40.

14. Consoni Filho E, Oliveira ASB, Schmidt B. Musculatura extra-ocular: um músculo esquelético diferenciado. Arq Bras Oftalmol. 1994;57(6):394-9.

15. Moraes CT, DiMauro S, Zeviani M, Lombes A, Shauske S, Miranda AF, et al. Mitochondrial DNA deletions in progressive external ophthalmoplegia and Kearns-Sayre syndrome. N Engl J Med. 1989;320(20):1293-9. Comment in: N Engl J Med. 1990;322(10):701.

16. Wallace DK, Sprunger DT, Helveston EM, Ellis FD. Surgical management of strabismus associated with chronic progressive external ophthalmoplegia. Ophthalmology. 1997;104(4):695-700.

\title{
XIII Simpósio Internacional da Santa Casa de São Paulo
}

\section{8 a 10 de Junho de 2006 \\ Frei Caneca Shopping \& Convention Center \\ São Paulo - SP}

\author{
INFORMAÇÕES: J DE Comunicação e Eventos \\ Tels.: (11) 5084-5284/5084-9174 \\ Fax: (11) 5574-8261 \\ E-mail: jdecomev@uol.com.br
}

